\title{
OVARIAN HYPERTHECOSIS: A RARE CAUSE OF HYPERANDROGENEMIA
}

Hepsiba Shanthi Kumar ${ }^{1}$, Dasharatha Murmu², Hesarghatta Asha Shyamsunder ${ }^{3}$, Rao Shyam Mohan $^{4}$, Chennappa ${ }^{5}$.

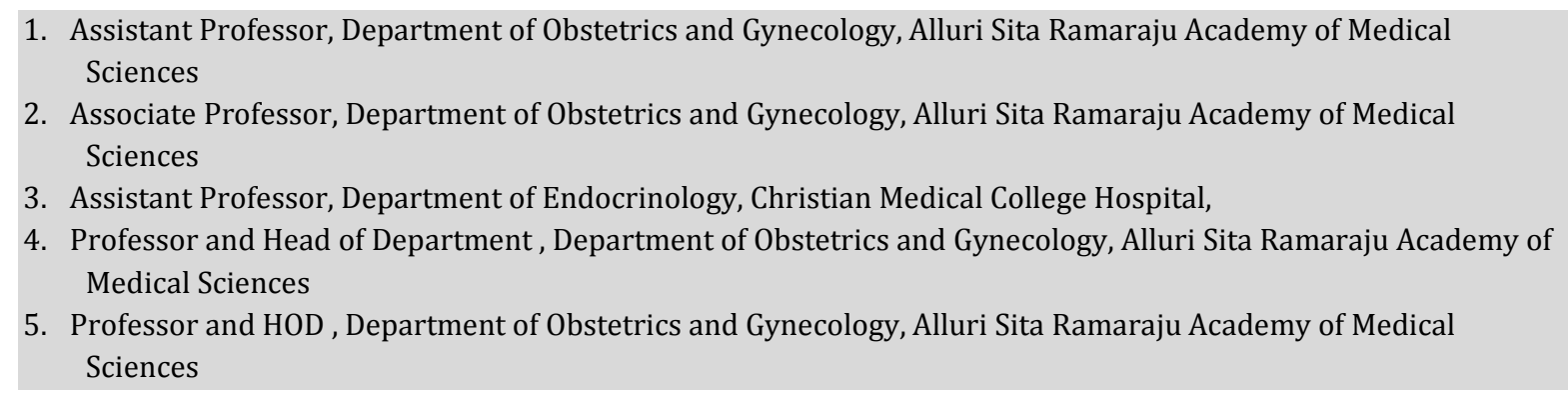

\section{CORRESPONDING AUTHOR:}

Dr Hepsiba Shanthi Kumar, C/O Dr. P S Peter Beersheba Hospital, Metpally, Karimnagar District, A.P.

E-mail: hepsibaskumar@yahoo.com

ABSTRACT: A 30 year old Indian woman presented to the ObGy Department with history of amenorrhea for two years associated with progressively increasing hirsuitism, clitoral hypertrophy and generalised hyperpigmentation of skin all over her body. On evaluation her serum testosterone was found to be elevated $(403 \mathrm{ng} / \mathrm{dl})$. Endocrine evaluation revealed glucose intolerance and a mild elevation in ACTH. CT Scan of the Abdomen and Pelvis revealed mildly enlarged ovaries bilaterally and normal adrenal gland anatomy. In view of an ovarian pathology she underwent wedge resection of both ovaries and histopathology of the ovaries was reported as ovarian hyperthecosis. Postoperatively she was given an antiandrogen flutamide and a short course of dexamethasone following which she resumed her menstrual function within 2 months and showed a improvement in androgenic symptoms after 6 months. Hence Wedge resection of ovaries followed by antiandrogens and corticosteroids postoperatively is an effective method of treating hyperandrogenic symptoms.

KEY WORDS: Ovarian hyperthecosis, HAIR -AN syndrome, Hirsutism, Clitoral hypertrophy.

INTRODUCTION: Ovarian hyperthecosis refers to patches of leutinized theca -like cells scattered throughout the ovarian stroma. It is characterised by the same histologic findings as seen in polycystic ovaries[1]. The clinical picture of more intense androgenisation is a result of greater androgen production. This condition is associated with lower LH levels, which is a possible consequence of higher testosterone levels blocking estrogen action at the hypothalamic-pituitary level [2,3]. A greater degree of insulin resistance is correlated with the degree of hyperthecosis[3]. In turn because insulin and insulin like growth factors-I (IGF-I) stimulate proliferation of theca interstitial cells.[4]. The follicles are unable to successfully change their microenvironment from androgen dominance to estrogen dominance, the change that is essential for continued follicular growth and development [5]. Insulin like growth factor binding proteins (IGFBPs) are found in follicular fluid allowing androgen dominance in the microenvironment [6,7]. Though this condition is 


\section{CASE REPORT}

seen primarily in postmenopausal women $[8,9,10]$, we have found this in a woman in her reproductive age.

MATERIALS AND METHODS: 30 year old Indian woman presented to us in Jan 2012 with history of secondary amenorrhea for 2 years. She attained menarche at the age of thirteen years . Regular menstrual cycles occurred every 30-40 days until October 2009 when her cycles became irregular and ceased completely since Jan 2010. She also noticed excessive generalised male pattern hair growth, enlargement of the clitoris and excessive darkening of the skin over the preceeding one year. There was no use of any medication. Past history and family history was unremarkable.

On Examination she was a young muscular female with height measuring $150 \mathrm{cms}$ and weight $55 \mathrm{~kg}$. She had hyperpigmented skin with significant hirsutism, Ferriman Gallaway score of 13(Figure1). Breast examination revealed Tanner stage II. There was no male pattern baldness or deep voice. Examination of external genitalia revealed clitoral hypertrophy of about $1.5-2 \mathrm{cms}$, with acanthosis nigricans in the groin bilaterally ( Figure 2). Labia appeared normal. The remainder of the examination was normal.

Initial tests showed elevated total testosterone - 403ng/dl, normal Follicle-stimulating hormone (FSH) , normal Thyroid-stimulating hormone, free T4, and Prolactin (Table 1) . In view of the elevated testosterone she was further evaluated to rule out a late onset congenital hyperplasia or an androgen secreting ovarian tumour. 17- hydroxy- Progesterone done was normal $(2.9 \mathrm{ng} / \mathrm{ml})$, Post-synacthen test showed no abnormal elevation( $3 \mathrm{ng} / \mathrm{ml}$ ). A normal Serum cortisol and DHEAS with normal Electrolytes ruled out a primary adrenal pathology. She was found to have mild glucose intolerance with Fasting Glucose of $129 \mathrm{mg} \%$, and postprandial glucose of $150 \mathrm{mg} \%$ and normal HbA1c - 4.4\% .

Transvaginal ultrasound revealed bilateral uniformly enlarged ovaries each measuring 5x4x5 cms, with increased ovarian volume and stromal thickness.

CT of Abdomen and pelvis with contrast: Hepatomegaly with fatty change. Bilateral enlarged ovaries measuring $6 \times 4 \times 3 \mathrm{cms}$ with dominant follicle on left side.

Radiograph of skull lateral view revealed a normal study.

In view of the ovarian pathology she underwent laparotomy and wedge resection of both ovaries under spinal anaesthesia on 2nd June 2012 at ASRAM, Eluru , A.P, India. Peroperatively both ovaries were found to be uniformly enlarged to $6 \times 5 \times 5 \mathrm{cms}$. Uterus, fallopian tubes and pelvis was normal. Histopathology of the Wedge biopsy revealed: Multiple sections from ovaries showing thickened cortex due to increased collagen and stromal hyperplasia. Discrete nests of luteinized cells are seen in some places which is suggestive of ovarian hyperthecosis (Figure 3).

Postoperatively she was treated with an antiandrogen Tab Flutamide $200 \mathrm{mg}$ twice daily and a short course of tapering dose dexamethasone $0.25 \mathrm{mg}$. She was also started on Metformin and Glimipride for the management of type II diabetes mellitus. Flutamide an oral, non-steroidal antiandrogen inhibits the function of dihydrotestosterone(DHT) by inhibiting $5 \alpha$ reductase which converts testosterone to DHT. Flutamide, is much less potent by weight and binding affinity than either spironolactone or cyproterone acetate,[14] but at the doses used, has usually been found to be more effective than either of them as an antiandrogen.[13,15] Alternative therapies which lower testosterone levels, such as orchiectomy or GnRH-analogue administration, have significant side effects such as hot flashes, decreased libido, muscle wasting, and bone loss. However, antiandrogen 
therapy alone is less effective than surgery. Dexamethasone is an exogenous steroid that provides negative feedback to the pituitary to suppress the secretion of ACTH and hence was used in this patient. A short course of dexamethasone has reduced the hyperpigmentation of skin dramatically.

RESULTS: The woman described in this report was found to have ovarian hyperthecosis and HAIR - AN Syndrome (Hyperandrogenemia, Insulin resistance and Acanthosis nigricans). Wedge resection of ovaries followed by anti-androgens and corticosteroids postoperatively has produced a significant improvement in her symptoms in terms of menstrual function, hirsutism and skin hyperpigmentation.

DISCUSSION: Ovarian hyperthecosis or stromal hyperthecosis with HAIR - AN Syndrome is a rare disorder clinically similar to PCOS but with greater intensity of androgenisation and is associated with insulin resistance and type 2 diabetes. Wedge resection of ovaries is known to reduce the levels of testosterone [12]. Postoperative treatment with an antiandrogen Tab Flutamide $200 \mathrm{mg}$ twice daily and a short course of tapering dose dexamethasone $0.25 \mathrm{mg}$, with Metformin and Glimipride for the type II diabetes resulted in resumption of normal menstrual function within 2 months. At 6 months we have found her to have less hirsutism especially less facial hair with significant reduction in hyperpigmentation (Figure 4). The unusual finding of an elevated ACTH was thought to be responsible for generalised hyperpigmentation of her skin. This feature dramatically improved following corticosteroid therapy.

These women are at an increased risk of cardiovascular disease due to hyperandrogenism. The ovarian secretion of large amounts of androgens in women with hyperthecosis means that peripheral estrogen production is increased. As a result, the risk of endometrial hyperplasia and endometrial carcinoma is increased, especially in postmenopausal women [11]. Hence routine evaluation for the above mentioned risks should be carried out at regular intervals.

\section{REFERENCES:}

1. Judd HL, Scully RE, Herbst AL, Yen SSC, Ingersol FM, Kliman B, Familial hyperthecosis: Comparison of endocrinologic and histologic findings with polycystic ovarian disease, Am J Obstet Gynecol 117;979,1973.

2. Nagamani M, Lingold GA, Morales AJ, Yen SSC, Inappropriate gonadotropin secretion in polycystic ovarian syndrome, J Clin Endocrinol Metab 82:3728,1997.

3. Nagamani M, Dinh TV, Kelver ME, Hyperinsulinemia in hyperthecosis of ovaries, Fertile Sterile 36:326, 1981.

4. Duleba AJ, Spaczynski RZ, Olive DL, Insulin and insulin like growth factor I stimulate the proliferation of human ovarian theca-interstitial cells, Fertil Steril 69: 335, 1998.

5. McNatty KP, Smith DM, Makris A, Degracia C, Tulchinsky D, Osathanondh R, Sciff I, Ryan KJ, The intraovarian sites of androgen and estrogen formation in women with normal and hyperandrogenic ovaries as judged by invitro experiments, J Clin Endocrinol Metab 50:755,1980.

6. Cataldo NA,Giudce LC, Follicular fluid from insulin-like growth factor binding protein profiles in polycystic ovary syndrome. J Clin Endocrinol Metab 74: 695, 1992.

7. San Roman GA, Magoffin DA, Insulin like growth factor binding proteins in ovarian follicles 
from women with polycystic ovarian disease: cellular source and follicular fluid, J Clin Endocrinol Metab75: 1010, 1992.

8. Goldman JM, Kapadia LJ, Virilization in a postmenopausal woman due to ovarian stromal hyperthecosis. Postgrad Med J. 1991;67(785):304.

9. Nagamani M, Hannigan EV, Dinh TV, Stuart CA Hyperinsulinemia and stromal luteinization of the ovaries in postmenopausal women with endometrial cancer. J Clin Endocrinol Metab. 1988;67(1):144.

10. Barth JH, Jenkins M, Belchetz PE , Ovarian hyperthecosis, diabetes and hirsuties in postmenopausal women, Clin Endocrinol (Oxf). 1997;46(2):123.

11. Nagamani M, Hannigan EV, Dinh TV, Stuart CA, Hyperinsulinemia and stromal luteinization of the ovaries in postmenopausal women with endometrial cancer. J Clin Endocrinol Metab. 1988;67(1):144.

12. IM Valcov, SI Documov.Effect of ovarian wedge resection for the stein lenthal syndrome on plasma FSH , LH, Testosterone, serum estradiol and on the responses of the pituitary to LHRHBJOG: An International Journal of Obstetrics \& Gynaecology, Volume 84, Issue 7, pages 539-542, July 1977

13. Robert S. Haber; Dowling Bluford Stough (2006). Hair Transplantation. Elsevier Health Sciences. p. 6. ISBN 978-1-4160-3104-8. Retrieved 28 May 2012.

14. Douglas T. Carrell (12 April 2010). Reproductive Endocrinology and Infertility: Integrating Modern Clinical and Laboratory Practice. Springer. p. 163. ISBN 978-1-4419-1435-4. Retrieved 28 May 2012.

15. Grigoriou O, Papadias C, Konidaris S, Antoniou G, Karakitsos P, Giannikos L (April 1996). "Comparison of flutamide and cyproterone acetate in the treatment of hirsutism: a randomized controlled trial". Gynecological Endocrinology: the Official Journal of the International Society of Gynecological Endocrinology 10 (2): 119-23. PMID 8701785

Table 1: biochemical evaluation

\begin{tabular}{|l|l|l|}
\hline Investigation & Patient's value & Normal reference values \\
\hline Total testosterone - & $403 \mathrm{ng} / \mathrm{dl}$ & Female: $50-120 \mathrm{ng} / \mathrm{dl}$ \\
\hline Follicle-stimulating hormone & $3 \mathrm{mIU} / \mathrm{mL}$ & $\begin{array}{l}\text { Female in reproductive age: } \\
4.7-21.5 \mathrm{mIU} / \mathrm{ml}\end{array}$ \\
\hline Thyroid-stimulating hormone & $3.67 \mathrm{mIU} / \mathrm{ml}$ & $0.5-4.70 \mathrm{mIU} / \mathrm{L}$ \\
\hline Prolactin & $4.68 \mathrm{ng} / \mathrm{ml}$ & Female Nonpregnant: $2.8-29.2 \mathrm{ng} / \mathrm{ml}$ \\
\hline 17- hydroxy- Progesterone, & $2.9 \mathrm{ng} / \mathrm{ml}$ & $0-19.2 \mathrm{ng} / \mathrm{mL}$ \\
\hline Serum cortisol AM & $16.8 \mu \mathrm{g} / \mathrm{dL}$ & AM: $4.3-22.4 \mu \mathrm{dL}$ \\
\hline DHEAS & $77.7 \mu \mathrm{dL}$ & Female Age $30-39: 45-270 \mathrm{ug} / \mathrm{dL}$ \\
\hline Na & $137 \mathrm{mEq} / \mathrm{L}$ & $135-145 \mathrm{mEq} / \mathrm{L}$ \\
\hline K & $3.7 \mathrm{mEq} / \mathrm{L}$ & $3.5-5 \mathrm{mEq} / \mathrm{L}$ \\
\hline Bicarbonate & $25 \mathrm{mmol} / \mathrm{L}$ & $22-29 \mathrm{mmol} / \mathrm{L}$ \\
\hline Fasting Glucose & $129 \mathrm{mg} \%$ & $70-110 \mathrm{mg} \%$ \\
\hline Postprandial glucose & $150 \mathrm{mg} \%$ & $<140 \mathrm{mg} \%$ \\
\hline HbA1c & $4.4 \%$ & $<5.7 \%$ \\
\hline
\end{tabular}




\section{CASE REPORT}

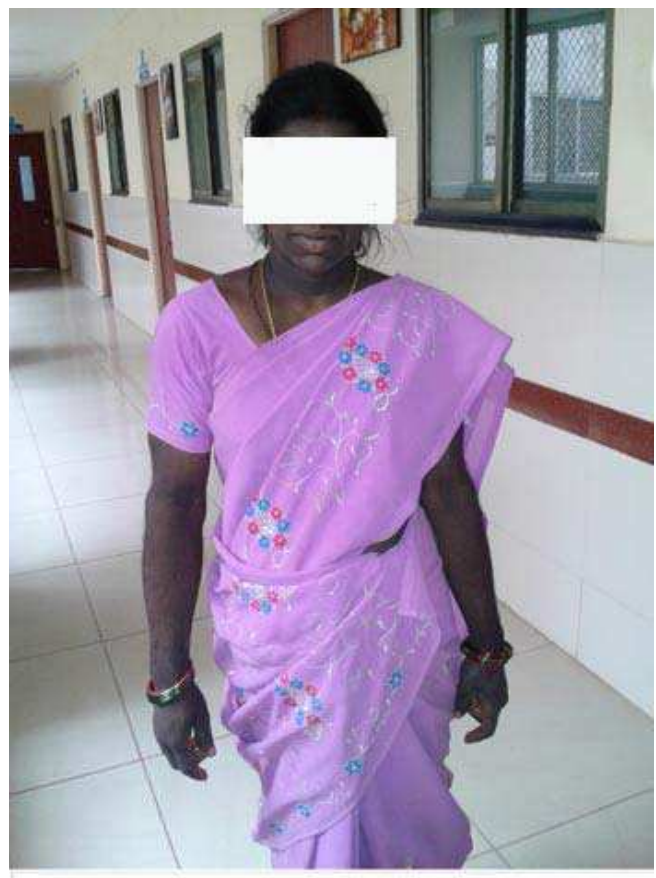

Figure 1: A young woman with significant hirsuitism, coarse facial features and darkened skin.

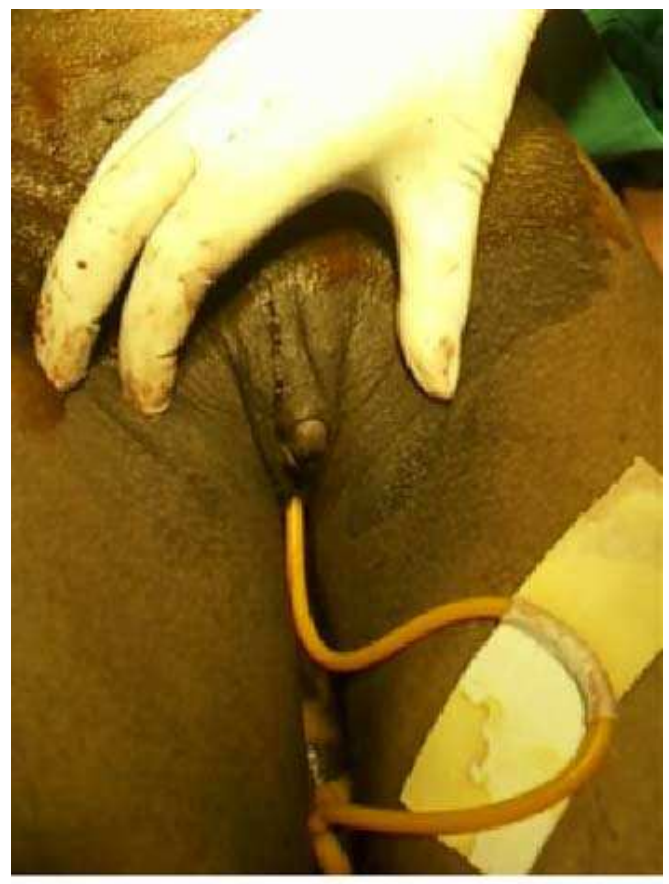

Figure 2: Clitoral hypertrophy with acanthosis nigricans of the groin



Figure 3: Section from ovary showing thickened cortex and stromal hyperplasia with discrete nests of luteinized cells suggestive of ovarian hyperthecosis 